Historia y comunicación social

ISSN-e 1988-3056

\title{
El teatro de la opinión. Prensa, política y lectura después de la revolución en el río de la plata
}

\author{
Hernán Pas ${ }^{1}$
}

Recibido: 11 de octubre de 2017. / Aceptado: 30 de septiembre de 2018.

Resumen. ¿Cuántos periódicos se vendían en Buenos Aires en los años que van de la Revolución a la caída de Juan Manuel de Rosas? La pregunta señala un punto oscuro en la historiografía de la prensa y de la cultura mediática argentinas, pero también en los estudios de historia política e intelectual, pues supone en su formulación otra no menos difícil de responder: ¿cuántos eran sus lectores? ¿Quiénes tenían acceso material a los impresos? El presente trabajo es un intento de avanzar en un terreno hasta ahora poco transitado del intercambio letrado en el siglo XIX. Dividido en dos partes, la primera presenta una descripción de los recursos formales y discursivos en la formación de la llamada opinión pública -centrada en los modos de ficcionalización de la opinión, a través de remitidos y correspondencias-, mientras que la segunda propone una aproximación analítica a su contraparte empírica, esto es, un examen de los posibles lectores concretos de periódicos, mediante el análisis de costos y salarios en dos períodos significativos y equidistantes.

Palabras clave: Prensa periódica; Opinión pública; Lectores; Siglo XIX; Consumo.

\section{[en] The theater of the opinion. Press, politics and reading after the revolution in the río de la plata}

\begin{abstract}
How many newspapers were sold in Buenos Aires in the years that go from the revolution to the fall of Juan Manuel de Rosas? The question point out a dark spot in the historiography of the Argentine press and editorial culture, but also in the studies of political and intellectual history, since it presupposes in its formulation another no less difficult to answer: how many were its readers? Who had material access to the newspapers? The present work is an attempt to advance in a field still little known of the culture lettered in century XIX. Divided in two parts, the first presents a description of the formal and discursive resources in the formation of the public opinion -centered on the modes of fictionalization of opinion, through announcements and correspondences-, while the second part proposes an approximation analytical to its empirical counterpart, that is, an examination of the possible particulars readers of newspapers, by analyzing the costs and wages in two significant and equidistant periods.
\end{abstract}

Keywords: Press; Public opinion; Readers; $19^{\text {th }}$ Century; Consumption.

Sumario: 1. Introducción. 2. Bajo la máscara del comunicado. 3. Suscripción y lectura. 4. A modo de conclusión. Bibliografía.

\footnotetext{
Universidad Nacional de La Plata, IdIHCS-CONICET.

hernan_pas@yahoo.com
} 
Cómo citar: Pas, H. (2019). El teatro de la opinión. Prensa, política y lectura después de la revolución en el río de la plata, en Historia y comunicación social 24 (2), 665-679.

\section{Introducción}

Hace ya algunos lustros, la prensa se ha convertido en objeto privilegiado de los estudios historiográficos y críticos. Al calor de las tesis de Jürgen Habermas, primero, y de Benedict Anderson sobre el fenómeno del print capitalism, después, la prensa periódica ha venido ocupando un espacio fundamental en los enfoques recientes de la historiografía política, literaria y cultural ${ }^{2}$. A su vez, nociones como las de "opinión pública", "público lector" "cultura política" y "espacio público" han sido revisitados críticamente desde un renovado interés por las condiciones materiales de producción textual.

Para el caso particular del Río de la Plata, y específicamente de Buenos Aires, contamos ya con una serie importante de trabajos historiográficos que han revisado el carácter ambivalente y coyuntural de la libertad de imprenta durante las primeras décadas de la República independiente ${ }^{3}$.

A pesar del visible interés de los últimos años, es notablemente exiguo lo que se sabe acerca de la efectiva circulación de los impresos, acerca de las tiradas y la cantidad de lectores (probables) con la que contaban esas empresas editoriales, acerca de los costos de la publicidad y de la lectura y, en consecuencia, acerca de las modalidades concretas de construcción letrada de un espacio público incipiente.

En este sentido, la cuestión material de la publicidad -en términos habermasianos-en el Río de la Plata ha quedado en penumbras, sobre todo durante la primera mitad del siglo XIX. Esto responde, en buena medida, a que se trata de un período institucionalmente convulsionado, cuyos registros deben buscarse en los mismos periódicos o en la correspondencia privada; por otra parte, como es bien sabido, el largo mandato de Juan Manuel de Rosas imprimió al espacio público un nuevo sentido al unanimismo revolucionario, fusionando opinión pública con dictamen oficial, y restringiendo en consecuencia la reproducción de impresos.

Ahora bien, si el período rivadaviano suele diferenciarse del rosista por su afán multiplicador de la opinión publicitada, hay que resaltar no obstante que el problema de las bases materiales de la opinión atraviesa todo el período y sigue siendo una incógnita de difícil resolución. En efecto, ¿cuántos ejemplares se vendían en Buenos Aires en los años que van de la Revolución a la caída de Juan Manuel de Rosas? ¿Puede establecerse un "crecimiento" de la lectura y, por ende, de los públicos lectores durante este período? Y si así fuera, ¿con qué herramientas examinar esa ampliación de la literacy?

La formulación de estas preguntas para un período previo al de la llamada modernización implica observar una serie de precauciones metodológicas insoslayables.

Cfr. Los espacios públicos en Iberoamérica, editado por François-Xavier Guerra y Annick Lempérière. (Ver referencia completa en Bibliografía). Ver, asimismo, Paula Alonso (comp.). Construcciones impresas. Panfletos, diarios y revistas en la construcción de los estados nacionales en América Latina, 1820-1920. Buenos Aires, FCE, 2004.

3 Ver, entre otros, los trabajos de Goldman (2000, 2008), Sábato y Lettieri (2003), Palti (2007), Molina (2009). 
Por un lado, no confundir lectores con suscriptores. Aun si el consumo letrado era, durante la primera mitad del siglo, más bien reducido, no deberíamos olvidar que la expansión de la lectura estuvo determinada en buena medida por la modalidad de lecturas "de prestado", que se extiende durante todo el período y que vendría a demostrar un circuito más amplio, no oficial o marginal de consumo.

Por otro lado, no superponer tiradas con ejemplares efectivamente vendidos o distribuidos. Se sabe que la mayoría de los periódicos eran sostenidos mediante suscripción oficial, es decir mediante prebenda gubernamental o estatal. Por último, resulta indispensable atender a la propia historia formal y técnica de la prensa periódica, esto es, una intrahistoria del impreso periódico que no necesariamente resulta coincidente con los vaivenes políticos ni responde exclusivamente a la lógica del uso, o apropiación estatal de los medios de prensa.

Atendiendo a estas premisas, intentaremos esbozar algunas respuestas a los interrogantes planteados más arriba. Para ello, nos apoyaremos en la prensa periódica seria o "culta" en un lapso que se extiende entre los años 1820 y los años 1850 , comenzando por el análisis de un periódico liberal cuyo título, Teatro de la Opinión, es ya una manifestación de la escenificación de la opinión en la república inestable e incipiente, y concluyendo con los principales periódicos del rosismo, La Gaceta Mercantil y, en particular, el Diario de la Tarde. A su vez, nos apoyaremos en algunos impresos previos - como El Censor, o La Prensa Argentina- a fin de volver más explícitos los mecanismos de interpelación al público lector.

El recorte apunta así a relevar un período temprano, complejo, cuya característica global es la permanente transformación y cuyo horizonte, no tan lejano, es el principio de estabilización que comenzará a regir en la prensa una vez superados los escollos políticos e institucionales.

\section{Bajo la máscara del comunicado}

El 25 de mayo de 1823 apareció en Buenos Aires un periódico cuyo propósito, según declaraba insistentemente, era fomentar y difundir "las opiniones". En el contexto de una ciudad todavía convulsionada por los sucesos del año 20, fomentar las opiniones significaba reivindicar una crítica (pretendidamente) ecuánime y no personalista, es decir, imparcial y razonada, ilustrada, no ministerial.

El periódico era redactado por Francisco Agustín Wright - uno de los primeros ingleses "nacionalizados" y futuro diputado del rosismo- y Ángel Saravia, y llevaba por título el simbólico nombre de Teatro de la Opinión. Acompañado por El Centinela, de Juan Cruz Varela, El Argos de Buenos Aires, La Gaceta Mercantil, de Esteban Hallet, que empezaría a salir a partir de octubre de ese mismo año, El Ciudadano Imparcial y El Republicano -todos periódicos adictos al gobierno de Martín Rodríguez y su ministro Rivadavia-, el Teatro de la Opinión procuraba distinguirse apelando a la libre opinión, por ende a la libertad de imprenta -cuya reglamentación empezaba a debatirse por esos años-, amparado en un lema recurrente de la época: "el único móvil de nuestras acciones fue y será siempre la salud pública" (Teatro de la Opinión, $\mathrm{N}^{\circ} 17,1823$, p. 268)4. "Salud pública” y "moral pública" eran, por

La paginación remite a la encuadernación en volumen del periódico. 
supuesto, los modos predilectos de la clase ilustrada de llamar al orden, esto es, de combatir los panfletos sediciosos y las revueltas que El Centinela tachaba de facciosas. Pero además de apoyarse en la opinión y difundirla, el periódico de Wright y Saravia buscaba también representar a la opinión pública. El carácter escenográfico y representativo del título, esto es, la apelación a la figura del Teatro como espacio donde la Opinión indefectiblemente debe ser representada es decisoria de un problema central que, con distintas modulaciones, atravesará toda la centuria y que, por cierto, llegará -nuevas tecnologías mediante- hasta nuestros días: la mediatización ( $\mathrm{y}$, en consecuencia, construcción) de la llamada opinión pública ${ }^{5}$.

Como es sabido, la noción de la "opinión pública" como tribunal calificado o fiscalizador proviene de una representación iluminista que apelaba al ámbito de la razón universal, y que atribuía además una concepción trascendental y filantrópica a la prensa periódica como instrumento de expansión de las "luces". Desde Jürgen Habermas (1962) a Keith Michael Baker (1987), todos los estudios advierten -con matices, como los del propio Baker para con Habermas- que el fenómeno estuvo ligado al proceso de secularización que llevó a "una crisis del poder absoluto", en cuyo contexto se apeló a "un principio de legitimidad exterior", amparado en la crítica ilustrada de los hommes de lettres, quienes asumieron un rol determinante en la formación del llamado "tribunal du public" (Baker, 1987, pp. 55-57). Ese rol, como una amplia bibliografía ya ha señalado, respondía a una necesidad de universalización de la opinión, representada de facto por el grupo ascendente que se arrogaba el dominio del intercambio racional ${ }^{6}$.

Ahora bien, representar a la opinión pública en Buenos Aires en la década del 20 significaba precisamente eso: su puesta en escena, su ficcionalización. Por ello, no debe sorprender que los remitidos, cartas o comunicados con que el Teatro de la Opinión llenaba sus páginas a fin de instalar la creencia de una efectiva circulación de opiniones reprodujeran, sin miramiento alguno, las ideas sostenidas por sus redactores. Es decir, los remitidos o cartas que supuestamente llegaban a la redacción no hacían otra cosa que confirmar la línea editorial del periódico. Confirmaban una opinión, y al mismo tiempo la representaban. Así ocurre, por ejemplo, con el remitido encabezado por "Un ciudadano que se cree más imparcial que el ciudadano imparcial, á los editores del Teatro"7, donde se lee:

Señores: hace tiempo que me siento con impulsos de escribir, pero la falta de un periódico donde insertar mis ideas libremente me ha contenido en el silencio. El Argos se propuso no admitir comunicados, y es sabido que el Centinela se come y priva de la luz pública [a] aquellos que bien no le parecen. Vds. por fin se manifiestan más francos publicando a diestra y siniestra las opiniones de todos los

Desde un ángulo distinto, pero complementario, Fernando Aliata ha observado en el diseño arquitectónico de la nueva Sala de Representantes inaugurada en mayo de 1822 una función modeladora de actitudes cívicas. Ver La ciudad regular..., cap. 6 .

6 Noemí Goldman (2008) ha distinguido diversos tempora en el uso y asimilación del concepto de opinión pública en Hispanoamérica: durante el periodo revolucionario la historiadora ha constatado su idealización conceptual; mientras que en la década del 20, concluidas las guerras de Independencia e iniciados los procesos representativos, se observa un viraje hacia una concepción legitimadora, como instancia reguladora superior, enfrentada por tanto a la "opinión popular" u "opinión mayoritaria".

7 El remitido hace referencia a otro periódico, El Ciudadano Imparcial, partidario del gobierno, publicado también en 1823 . 
hombres, y si algunas de ellas aparecen alguna vez animadas de un espíritu o pasión particular; nada importa cuando el público es juez y no falta quien describa el amberso (sic) de la medalla (Teatro de la Opinión, ídem, 265).

Ante la parcialidad o discrecionalidad de los otros periódicos, el Teatro de la Opinión se presenta como un espacio franco, un medio por el cual las opiniones circulan moderadas y sin trabas. Abundan, en este sentido, los remitidos que llevan por encabezado "A los Sres. Editores del Teatro", en los que se tematizan intereses de orden público o policial, como se decía en la época, o se corroboran posicionamientos ante la prensa -las críticas al Ciudadano Imparcial y a El Centinela, por ejemplo, se apoyan también en el uso de remitidos-.

No es improbable que Wrigth y Saravia hayan recibido colaboraciones anónimas en forma de correspondencias, pero lo cierto es que la precariedad institucional, así como la poco extendida literacy restringían el uso del buzón de la prensa. En su lugar, los periódicos optaban por escenificar sus interlocuciones. Tal vez no haya habido mejor confesión de partes sobre este procedimiento, extendido durante varias décadas, que aquella que escribiera Juan Bautista Alberdi a comienzos de 1840 en Montevideo. En uno de los periódicos que publicó allí junto con Juan María Gutiérrez antes de su viaje europeo, declaró:

El comunicado es a veces el periodista mismo, que, teniendo deseos de decir alguna insolencia o alguna animosidad indigna [...], toma la máscara de 'un suscritor [sic] o de un imparcial', dice su torpeza, arroja luego la máscara y vuelve a presentarse muy orondo y muy serio a tratar de los altos intereses del país. La 'correspondencia' es una perpetua farsa de 'carnaval', una mascarada continua, donde pobres diablos se disfrazan de 'padres de familia, de ciudadanos, de patriotas, de amigos de la razón', como los taberneros se visten de duques y reyes en las noches de carnaval. Bajo la máscara del comunicado, todo el mundo se ve dispensado de la buena educación y de los buenos estilos: firmarse 'un ciudadano, un imparcial' $\mathrm{y}$ volverse un marinero, un soldado en su lenguaje, es todo uno; lo que da lugar a creer que la verdadera careta, el verdadero disfraz es el que traen en la sociedad cuando se presentan como gentes educadas y civiles; y que nunca están menos enmascarados que cuando están enmascarado. (El Talismán, n 16, 27/12/40, p. 2).

Según la descripción auto-irónica de Alberdi, la máscara del comunicado encubre no sólo a su verdadero autor -la mayoría de las veces, como dice Alberdi, "el periodista mismo"-, sino que también parece encubrir la falta o carencia efectiva de comunicados.

Otra inflexión política de este enmascaramiento se había producido algunos años antes, cuando en 1815 el Directorio aprobó el Estatuto Provisional del nuevo Estado. En ese documento, que reponía el Decreto sobre libertad de Imprenta del 26 de octubre de 1811 -sancionado por la primera Junta-, se creaba, por un lado, la Gaceta oficial del gobierno y, por otro, se preveía y consignaba la creación de un periódico opositor, al que incluso se le adjudicaba título y funciones explícitas. El articulado en cuestión, decía:

Se establecerá un Periódico encargado a un sugeto de instrucción, y talento, pagado por el Cabildo, el que en todas las semanas dará al público un pliego o más con el 
título de Censor. Su objeto principal será reflexionar sobre todos los procedimientos y operaciones injustas de los funcionarios públicos y abusos del País, ilustrando a los Pueblos en sus derechos y verdaderos intereses (Estatuto, cap. 2, art. VI).

El futuro redactor de ese periódico opositor, designado también por el gobierno, fue el exiliado cubano Antonio José Valdez ${ }^{8}$. Ahora bien, ese mismo Estatuto garantizaba a partir de 1815 la libre apertura de imprentas, de modo que cuando comenzaba a publicarse el periódico oficial de Valdez se abría otra imprenta a cargo de Manuel José Gandarillas - propiedad del comerciante chileno Diego Barros, padre del futuro historiador Diego Barros Arana-, conocida como Gandarillas y Cía -que luego se transformaría en Imprenta Benavente y Cía. - En consecuencia, a poco de hacerse cargo de El Censor, en septiembre de 1815, Valdez se vio tentado de publicar otro periódico por la imprenta recientemente instalada. Esta vez, en cambio, se trataría de un periódico en el cual, bajo el resguardo del anonimato, el cubano ejercería verdadera oposición al gobierno.

Este segundo periódico de Valdez, en el que hacía verdadera crítica al gobierno, se llamó La Prensa Argentina. Salía los martes - mientras que El Censor se publicaba los jueves-, y, a diferencia del primero, en sus páginas había lugar para la ironía y la crítica satírica. Con un formato similar al del resto de la prensa del período, esto es, un pliego de ocho páginas a una columna -casi un libro en entregas-, La Prensa Argentina tenía una sección final llamada "Impresos" en la que su redactor pasaba revista a lo publicado en la prensa local, en general con afán polémico. "Tengo un almacén de garrotes", había anticipado en el Prospecto. Y, claro, los garrotes también debían ser para El Censor, entablando así una farsa desopilante, si bien señalada por casi todas las historias de la prensa argentina no del todo dimensionados sus alcances. Por ejemplo, con claro tono irónico, Valdez se burlaba en La Prensa Argentina sobre lo que había escrito él mismo en El Censor: "Censor número 6. Copia el decreto del amo, y lo combate fieramente. ¡Qué insurgente es el censor! ¡Cáspita!’. ( $L a$ Prensa Argentina, $\mathrm{N}^{\circ}$ 4, 03-10-1815, p. 6)

Valdez también pudo aprovechar ese desdoblamiento para efectuar una crítica más a gusto, más suelta, publicitando en un periódico -El Censor- escritos a ser discutidos en el otro -La Prensa Argentina-, como ocurre con la correspondencia aparecida en El Censor y firmada con las siglas J. V. G. -o sea, anónimamente-, que Valdez decide publicar a los efectos de mejor discutir sus argumentos desde su otro periódico 9 .

Es muy probable que el anonimato de Valdez fuera relativo, sobre todo si se piensa en el estrecho círculo de la élite letrada. No obstante, si se leen los entredichos

\footnotetext{
Noemí Goldman se ha detenido parcialmente en este episodio en su trabajo "Libertad de imprenta, opinión pública y debate constitucional en el Río de la Plata (1810-1827)”.

9 Decía, sobre el final, esa correspondencia: "En un país donde cada hombre no tiene en su casa alaja de mas aprecio que el fusil, sable y pistolas y donde hasta los niños no tienen más juguete que las armas, pega muy mal eso de garrotes; la moderación es el carácter de este pueblo aguerrido, y todo papel que no esté concebido en este delicioso estilo, tendrá tan mala acogida como la crítica de la carta del padre Castañeda" (El Censor, N ${ }^{\circ}$, 19-10-1815, p. 8). En su respuesta al anónimo, Valdez deja vislumbrar algo de los lazos intergrupales: "al ver la zurribanda -dice en La Prensa- que se me descarga en el Censor, creí en el pronto que algún censor añejo [referencia a Pazos Kanki, redactor de El Censor de 1812] me había robado del almacén alguno de mis garrotes [...] Ya sabe V. señor público, que toda clase de madera no es a propósito para esta especia de armas." (La Prensa Argentina, No 7, 24-10-1815, p. 2).
} 
entre la Gaceta oficial del gobierno y La Prensa Argentina, parecería que la comedia alcanzó su cometido. A diferencia de lo que ocurría con los cruces preestablecidos entre la Gaceta y El Censor, con La Prensa Argentina los redactores de la Gaceta se despacharon de modo furibundo, y sólo la doble autoría enmascarada de Valdez pudo contribuir al aplacamiento de la polémica. En respuesta a un arrebatado artículo de La Gaceta, Valdez escribía:

Gaceta numero 23 [...]. Se incluye un articulo comunicado que parece puro y duro de la pluma del editor. En el se le dice al prensista con ayre magistral, pueril, criminal, frivolo, impertinente, folletista, burlesco, ridiculo, absurdo, fraudulento y otras lisuras pesadas, que si no fuese por su genio bonazo se hubiera enojado mucho (La Prensa Argentina, No 5, 10-10-1815, p. 5).

Evidentemente, la ficción montada por Valdez funcionó en alguna instancia del intercambio público. Es posible que para el redactor de La Gaceta de Buenos Aires -por entonces el chileno Fray Camilo Henríquez-, La Prensa Argentina fuera otro montaje del discurso faccioso. Como sea, la comedia parece haber tenido efectos concretos en el acotado espacio de discusión pública de la élite, lo que sugiere el potencial simbólico del anonimato y de la reproducción de impresos en la construcción de la llamada opinión pública.

\section{Suscripción y lectura}

Para que esta comedia de la opinión publicitada cobrara carnadura durante las primeras décadas de la Independencia era necesario, cada vez más, contar con una contraparte empírica sustentable, es decir con un público lector suficientemente extendido como para que esa opinión excediera al menos el horizonte tertuliano. A ello parecía apuntar Valdez contra lo dicho en La Gaceta de Buenos Aires del 9 de septiembre de 1815 en un artículo titulado, sintomáticamente, "De la excesiva multiplicación de los periódicos", en la que su redactor se despachaba contra el "cualquierismo" al que habilitaba, según esa visión, la prensa ${ }^{10}$. Ante lo cual, el cubano respondía:

Concluye la gaceta con un discurso sobre la excesiva multiplicación de los periódicos [...]. Señor editor, esa crítica tendría lugar en otra parte; pero hacerla en Buenos Aires, donde se publican solamente tres pliegos de papel semanales no da a entender otra cosa que las cosquillas que le ha hecho a V. la Prensa Argentina ( $L a$ Prensa Argentina, № 2, 19-09-1815, p. 7).

Comparar Londres con Buenos Aires, sostiene el cubano, es un despropósito. Las cifras históricas, desde ya, le daban la razón. Miles de suscriptores en las metrópolis europeas destronaban cualquier atisbo de analogía con la escasez de las listas sudamericanas. Un dato que contribuiría a reponer esa brecha empírica sería el de

10 Este tipo de textos manifiesta el unanimismo que estaba por imponerse en la prensa revolucionaria. Decía, entre otras cosas, así: “Qualquiera se juzga bastantemente hábil para llenar un pliego de papel, y emprende este trabajo sin talentos, ciencia, ni discernimiento. De aquí resultan tantos papeles frívolos, llenos de lugares comunes, y de rumores vagos con el nombre de noticias..." (La Gaceta de Buenos Aires, No 20, 09/09/1815, p. 4, col. 1). 
la tirada y efectiva circulación de los periódicos de la época: ¿cuántos ejemplares se editaban, vendían o circulaban -dando por descontado que edición, venta y circulación no son sinónimos- de El Argos de Buenos Aires, el Teatro de la Opinión o La Gaceta Mercantil? En este punto, la historiografía de la prensa mantiene un déficit hasta ahora difícil de saldar. No contamos todavía con datos ciertos respecto de la efectiva cantidad de periódicos editados y/o vendidos, y mucho menos de la cantidad -siquiera probable- de lectores con los que podía contar un periódico en Buenos Aires.

En un típico alegato de autopromoción, Domingo F. Sarmiento, al iniciar en 1842 la publicación de El Progreso en Santiago de Chile y solicitar el beneplácito del público, escribió:

Hay en Buenos Aires y los ha habido de veinte años atrás 2000 y 3000 suscriptores a los diversos diarios. En Montevideo pasan de mil [los] abonados a diarios en castellano, en francés, en inglés, en italiano; en Lima mismo el Comercio tiene más de ochocientos; y en Santiago no pueden obtenerse los indispensables para mantener una publicación naciente y cuya extensión, interés e importancia estará siempre en relación del número de suscriptores (Pas, 2013, p. 148).

La primera pregunta que surge de lo dicho por Sarmiento es: ¿cuál es la cantidad indispensable de suscriptores para que un diario de los años 1840 pueda mantenerse en plaza con relativa autonomía? Si en Santiago de Chile y en Valparaíso los periódicos publicados -los más importantes: El Mercurio, El Araucano, La Gaceta del Comercio- oscilaban entre los 300 y 500 ejemplares -contando la suscripción oficial, que se llevaba entre 100 y 200-, ¿qué justifica, más allá del recurso estratégico de autopromoción, la cifra exuberante de 2000 o 3000 suscriptores dada por Sarmiento? En verdad, no hay suficientes datos fidedignos acerca de la cantidad de ejemplares que circularon en Buenos Aires durante los años 30 y 40.

Para el final de este período, la fuente inevitable son las Memorias de Benito Hortelano. El editor y publicista español arribó a Buenos Aires un año antes del derrocamiento de Juan Manuel de Rosas. Luego de los sucesos de febrero del 52, Hortelano se asocia con Mitre y fundan Los Debates, periódico que consiguió, según ha dejado consignado en sus Memorias, la cifra inigualable hasta entonces de 2.300 suscriptores ("cosa sin ejemplo en estos países", acotará sin falsa modestia Hortelano (1936, p. 196)).

Como contrapartida, las escasas listas de suscriptores que se conservan de los periódicos de la época resultan documentos valiosos a la hora de tentar la cantidad de ejemplares en circulación. Si bien representan a un público selecto, y no del todo fidedigno en cuanto a la extensión real de la lectura (hay que tener presente el sistema de préstamos o lecturas colegiadas), ofrecen una idea aproximada no sólo de la cantidad de lectores, sino de su variabilidad a lo largo de las décadas y aun de una publicación a otra. Se conocen, por ejemplo, dos listas de suscriptores del Telégrafo Mercantil: la primera arroja un número de 237 suscriptores de los cuales 160 pertenecen a la ciudad de Buenos Aires y el resto a otras provincias, y la segunda apenas la supera en 246, de los cuales 146 eran habitantes de la ciudad y el resto de otras provincias y ciudades. Por estos números y otras suscripciones esporádicas se concluye que el Telégrafo... tiraba entre 300 y 400 ejemplares. (Furlong 1953, I, pp. 272ss.) 
Dos décadas después, la ecuación no parece haber variado mucho. En 1824, El Argos de Buenos Aires da a conocer su lista de suscriptores: sumaban un total de $156^{11}$. Entre ellos, hay que contabilizar al Gobierno, que se suscribe por un total de 30 ejemplares, y al Banco, que suscribe 2 . En total, son 186 periódicos los vendidos por suscripción. En consecuencia, entre éstos y los 2300 de Los Debates que recuerda Hortelano existe una gradación, pausada por diversos factores, entre los cuales los cambios técnicos y tecnológicos de los impresos no resultaron menores, lo que demuestra las exageraciones de Sarmiento.

El desinterés por la suscripción a la prensa fue en general adjudicado o bien a la nula o poca instrucción de la sociedad -incluyendo a los miembros de las élites políticas-, o bien a la inestabilidad institucional o bien a la divergencia entre plataformas discursivas y apetencias lectoras -aspecto este que cobraría cada vez más importancia, acompañando los procesos de modernización de la prensa en la región--. La dominante figura de la "lectura de prestado" se extiende desde el Telégrafo Mercantil hasta por lo menos El Mosquito en los inicios de la década de $1860 .{ }^{12}$ Ante lo cual, cabe formular la pregunta por el coste material que implicaba entonces la lectura periódica. En principio, ¿cuál era el valor relativo de un impreso, si se tiene en cuenta el costo de vida aproximado de un trabajador asalariado medio, o el de un trabajador libre para esta primera mitad del siglo XIX?

Con los recaudos del caso, voy a aprovecharme aquí de los últimos estudios historiográficos sobre series de salarios y precios a fin de bosquejar, para determinados años o lustros, un cuadro lo más aproximado posible, que nos permita incorporar un elemento decisivo -como lo es el costo de un impreso en la economía doméstica de un trabajador medio- en el análisis del lectorado. Como exige la mayoría de los estudios aquí tratados, hay que decir que aún no contamos con datos contrastables que puedan conformar series fidedignas, entre otras cosas por la complejidad de las fuentes y por las dificultades metodológicas que representa la construcción precisa y contextualizada de las variables que inciden en la construcción de los salarios. En este sentido, debe llamarse la atención acerca de que el salario no era ni el único ingreso o estipendio doméstico - hay que agregar las pagas en especies, alojamiento, vestimenta, los llamados "vicios", como el tabaco-con el que contaba un trabajador, ni, tampoco, el más difundido ${ }^{13}$. Con todo, una aproximación tentativa a la composición del salario promedio -ingreso monetario y estipendio anexo- permitirá proyectar el costo relativo de la suscripción periódica en una economía doméstica media y, de ese modo, bosquejar una hipótesis más sólida acerca del consumo y la expansión de la lectura en Buenos Aires hacia mediados de siglo.

Entre los años 1823 y 1824, cuando aparece La Gaceta Mercantil y el ya citado Teatro de la Opinión, un maestro de escuela (de ciudad o de campaña) ganaba 25

11 La lista se publica fragmentada, entre el número 4, del 28 de enero y el número 8, del 11 de febrero de 1824.

12 En el prospecto del Telégrafo, por ejemplo, se lee: “¿Qué dirá el hombre de Corte, de aquel que aun con proporciones muchas (por no gastar dos pesos) anda, corre, y aun vuela por leer de gorra el telégrafo en los Cafés, y casa del Amigo?" (Furlong II, 239). Y en 1863, a poco de aparecer, el semanario de H. Meyer se burlaba de "los lectores de ojito / los lectores de mogolla". (Roman 2017)

13 Como sostiene Lyman L. Johnson (1990), suponer la existencia de un empleo continuo, regular con salario tergiversa de manera burda las experiencias de empleo claramente observables en las fuentes. Ver, asimismo, el trabajo de Julio Djenderedjian y Juan Luis Martirén (2016), en el que se discute la metodología comparatista dominante en los estudios del norte, y se aportan sustanciales datos sobre salarios e ingresos en estancias de Corrientes, Entre Ríos, Santa Fe, Banda oriental y Buenos Aires. 
pesos de salario mensual, un cabo del ejército prácticamente la mitad, 12 pesos, y un peón o jornalero de oficio podía llegar a ganar entre 1,5 y 2 pesos diarios. En ese mismo lapso, una libra (medio kilo aprox.) de azúcar blanca del Brasil costaba $\$ 0,44$; una arroba de carne (alrededor de $11,5 \mathrm{~kg}$.) $\$ 2$, y una libra de yerba paraguaya -de uso habitual- $\$ 1,1 ; 4$ velas de sebo costaban $1 / 2$ real; y un par de zapatos (de hombre) costaba $\$ 3$. A su vez, la visita de un médico se pagaba $0,50 \operatorname{pesos}^{14}$.

La Gaceta Mercantil, que apareció en octubre de 1823 y se publicaba diariamente salvo los domingos, comenzó cobrando una suscripción mensual de $\$ 2$, y de $\$ 4$ si el suscribiente pretendía colocar sus avisos gratis. Otros periódicos de ese año, como $E l$ Teatro de la Opinión, El Centinela o El Argos de Buenos Aires, todos de publicación semanal, cobraban entre 1,5 y 2 pesos la suscripción trimestral, y aproximadamente 1 real el pliego suelto. ${ }^{15}$ Es decir que la suscripción mensual o trimestral a un impreso periódico oscilaba entre $\$ 1,5$ y $\$ 2$; el monto era equivalente entonces a 3 o 4 libras de azúcar, a una arroba de carne, a casi dos libras de yerba, a 96 velas de sebo -como mínimo-, a más de la mitad de un par de zapatos y a 4 visitas médicas. Y era equivalente también al sueldo diario de un jornalero de oficio, al 16\% del salario mensual de un cabo o soldado del ejército, o al $8 \%$ del salario mensual de un maestro.

La variabilidad e inestabilidad monetaria de la época ha sido señalada por todos los historiadores que han reconstruido las finanzas y la economía posrevolucionaria de Buenos Aires. La guerra con el Imperio lusitano de 1827 en general es señalada como instancia decisiva en la depreciación de la moneda, depreciación que a partir de entonces no dejará de acrecentarse (Amaral 1981). De modo que casi una década después, entre los años 1832 y 1833, la brecha entre el costo de vida y el salario medio de un trabajador va a ensancharse notablemente, restringiendo aún más el comercio del impreso.

En 1832, La Gaceta Mercantil había llevado la suscripción mensual a 7 pesos, y cada número suelto costaba 3 reales; exactamente lo mismo cobraba el Diario de la Tarde -que había aparecido en mayo de 1831, cobrando 5 pesos-, y El Lucero, otro de los periódicos emblemáticos del régimen rosista, redactado por Pedro de Angelis (aunque no perduraría más allá del año 1833). Y lo mismo cobraba, se podría decir, The British Packet, el periódico semanal inglés de Thomas G. Love que comenzó a salir en agosto de 1826 y que llegaría, como los dos primeros, hasta el umbral de Caseros $^{16}$.

Por estos años, 1832 y 1833 , el sueldo mensual de un cabo rondaba los $\$ 18^{17}$; a su vez, un jornalero de oficio percibía 1,5 pesos diarios, un peón rural mensualizado obtenía alrededor de 25 pesos, y prácticamente lo mismo percibía un Capataz de estancia $^{18}$. Los comestibles y artículos de vestir rondaban los siguientes precios: una

14 Los datos han sido tomados de varias fuentes: Barba (1999). Halperin Donghi (1982); Jorge Gelman y Daniel Santilli (2014); y María Alejandra Irigoin (1995). También de impresos de la época. Ver referencias bibliográficas.

15 El Centinela, por ejemplo, cobraba 1 real por número suelto y solicitaba suscripción por trimestre. Es decir que el total de la suscripción era de 12 reales, lo que equivale -en moneda de la época-a aproximadamente 1,5 pesos fuertes.

16 The British Packet cobraba una suscripción mensual de 7 dólares.

17 El sueldo de un cabo era de \$14,62 en 1832, pero de \$24 en 1834.

18 Los años 1832, 1833 son bastante estables en fluctaciones del valor de la moneda, y los salarios del peón rural y del capataz se asimilan bastante, lo que cambiará en la década de 1840, observándose una distancia mayor en la especialización. (Cfr. Gelman y Santilli 2014). El peón rural (el capataz de estancia) cobraba entre 19 y 20 pesos en 1831, pero entre 29 y 30 pesos en el año 1833, de allí que hayamos optado por el promedio. 
libra de azúcar blanca del Brasil oscilaba entre 0,96 y 2 pesos; una arroba de carne se mantenía entre los $\$ 2$ y $\$ 2,5$; una libra de yerba paraguaya salía $\$ 2,75 ; 4$ velas de sebo costaban 2 reales; un par de zapatos (de hombre) entre $\$ 16$ y $\$ 20$, y la visita de un médico alcanzaba los $\$ 2$. Además, un frasco de vino de Burdeos -aproximadamente, $2 \frac{1}{2}$ litros- costaba $\$ 20$; un sombrero de castor a prueba de agua -que a finales de la Colonia se pagaba 12 pesos- en 1832 salía 35 pesos; alquilar un cuarto con vista a la calle y con patio en el centro de la ciudad -Potosí $\mathrm{N}^{\circ} 92$ - podía valer 40 pesos al mes; y el palco para una función lírica del teatro se pagaba $\$ 10^{19}$.

De manera que el monto de una suscripción mensual a cualquiera de los 4 periódicos mencionados era equivalente a 5 libras de azúcar, a tres arrobas de carne, a 2 $1 / 2$ libras de yerba ${ }^{20}$, a más de 100 velas de sebo, a más de la mitad del costo de un par de zapatos y correspondía aproximadamente a 4 visitas médicas. Representaba, a su vez, alrededor de la quinta parte de un alquiler en el centro, y el $70 \%$ de un palco para una función teatral. Y si se consideran los sueldos promedio estipulados para trabajadores rurales y militares, tenemos que, por estos años, la suscripción mensual a un periódico correspondía a $4 \frac{1}{2}$ veces el sueldo diario de un jornalero de oficio, a casi el $40 \%$ del salario mensual de un cabo del ejército, y a casi un $30 \%$ del salario de un peón mensualizado o a un capataz de estancia. Aun con la salvedad que hicimos más arriba respecto de la composición real de la economía doméstica de un trabajador medio en la Buenos Aires de la época, puede percibirse que, al menos en los inicios de la década de 1830, el costo de la lectura diaria era relativamente alto, lindando con el consumo de un bien suntuario, en particular para la llamada clase popular -jornalero, peón rural, capataz, cabo, soldado- ${ }^{21}$.

Por cierto, el costo relativo de un impreso no determina su alcance comunicativo. Además del valor de la suscripción, otro indicio a tener en cuenta a la hora de intentar mensurar la circulación de la prensa son los puntos y lugares de venta y consumo. Si bien durante todo el período prevalecen las prácticas de lectura colegiadas, siendo los sitios de sociabilidad pública, como los cafés o la Biblioteca, los principales espacios de adquisición y lectura de impresos periódicos, los lugares de venta pública son asimismo representativos de su alcance social y comercial. En este sentido, durante los primeros lustros de la Independencia, los periódicos eran adquiridos en pocos y a la vez preestablecidos lugares de comercialización.

Durante la década que se extiende entre 1815 y 1825, la mayoría de los periódicos impresos en Buenos Aires ofrecen como sitio de venta al público -y como lugar de suscripción- a la "tienda de Ochagavia", o "vereda ancha", como se conocía por entonces el sector sur de la Plaza de la Victoria (luego 25 de Mayo), donde estaba ubicada la Recova Nueva. El edificio de la Recova -que para 1818 no había sido aún terminado- iba de calle Defensa a calle Bolívar - sobre la actual Hipólito Irigoyen-, y a esa mitad de cuadra en construcción se la apodaba "vereda ancha", zona de ventas de todo tipo. (Hay que tener en cuenta que esa era la zona de la legislatura provincial, conocida entonces como Sala de Representantes, que funcionaba en la esquina de Perú y Alsina, en la cuadra de la célebre Manzana de las Luces, donde

\footnotetext{
Algunos de estos datos fueron extraídos de La Gaceta Mercantil, 01/04/1832, 07/04/1832, 09/05/1832.

La ración mensual media de yerba mate para una familia de trabajadores era de 4 libras.

21 Precisamente, a ese sector particular de la sociedad estaban dirigidos en buena medida los impresos populares de Luis Pérez. Ver nota 6.
} 
también se situaban la Biblioteca Pública y la Universidad) ${ }^{22}$. Es decir, que la dicha tienda de Ochagavía se ubicaba en un lugar estratégico en términos políticos y sociales, equidistante de los edificios más importantes de la administración pública. ¿Cuáles eran los periódicos que se vendían en dicha tienda o "vereda ancha"? Todos, o casi todos: El Censor (1815), Los Amigos de la Patria y de la Juventud (1815) El Observador Americano (1816), El Independiente (1816-1817), La Estrella del Sud (1820), El Argos de Buenos Aires (1821-1825), El Centinela (1822), El Correo de las Provincias (1822); El Teatro de la Opinión (1823), El Republicano (1823), y a ellos habría que sumar seguramente muchos otros que, dada la rudimentaria publicidad de la época, no se molestaban en notificar al respecto.

El mapa de la comercialización de los impresos sugiere que se trata, en esta primera etapa al menos, de un público político, mayoritariamente perteneciente o cercano a las élites dirigentes. Esa concentración material, social y discursiva de la prensa comenzará a alterarse en el segundo lustro de la década del 20, para disiparse y convertirse definitivamente en otra cosa hacia mediados de la década siguiente. El impase del rosismo -durante su mandato, los tres periódicos oficiales, La Gaceta Mercantil, el Diario de la Tarde y The British Packet, recibían suscripciones en sus respectivas imprentas (el semanario inglés, The British Packet, hasta tener imprenta propia, se editaba por la imprenta de La Gaceta Mercantil, de Esteban Hallet, calle Cangallo)-, será definitivamente superado hacia fines de la década de 1840 con la aparición de algunos nuevos periódicos como el Diario de Avisos (1849), o El Agente Comercial del Plata (1851), que devendrá Los Debates (1852), y que estipulaban como puntos de venta ya no calles o imprentas, sino ciudades, barrios o provincias: en Buenos Aires, \$25 por mes; en la Boca y en Barracas, \$30 por mes; en Provincias, \$6 fuertes por trimestre; en Montevideo, $\$ 20$ pesos plata por mes.

A su vez, la diversificación podrá observarse también en el reemplazo progresivo de tiendas y almacenes por librerías, como sitios específicos de comercialización de la prensa, y en las propuestas editoriales, que hacia fines de esa misma década no dejarán de explorar -como muestran los casos del Diario de Avisos, el Agente Comercial del Plata- las novedades técnicas expandidas por la mundialización de la cultura impresa.

El Diario de la Tarde es una muestra paradigmática de una diversificación lectora creciente en la Buenos Aires rosista, y lo es precisamente por su carácter oficial. Fundado en 1831, el impreso fue progresivamente explorando una propuesta editorial distanciada de lo partisano (a diferencia, por ejemplo, de lo que ocurriría con La Gaceta Mercantil). En efecto, si se repasan las primeras páginas del primer lustro de su publicación, exceptuando algunos documentos oficiales y noticias locales relativas o bien a los debates parlamentarios a raíz de la renuncia de Rosas, o bien a determinados conflictos con los indios, la mayoría de los textos que encabezan diariamente la publicación pueden muy bien catalogarse bajo el rótulo variedades: noticias del exterior, mayormente de Inglaterra y Francia, correspondencias, memorias, textos "literarios" diversos, como las crónicas sobre el Niágara, o relatos extraídos de pe-

22 "Manzana de las Luces" bautizó nada menos que El Argos de Buenos Aires a la cuadrícula conformada por las calles Alsina, Moreno, Bolívar y Perú, donde entonces se ubicaban el templo de San Ignacio (luego Colegio), la Biblioteca Pública, la Academia de dibujo, la Universidad y la Sala de Representantes. Cfr. El Argos de Buenos Aires, $\mathrm{N}^{\mathrm{o}} 2,1^{\mathrm{o}}$ de septiembre de 1822 , p. 138. 
riódicos franceses, como la nouvelle de Delphine de Girardin, El lente, publicada el 20 de noviembre del mismo año.

Por lo demás, el Diario de la Tarde fue el primer periódico de Buenos Aires en publicar un folletín entre sus páginas, y no cualquier folletín. En marzo de 1846 apareció en el zócalo del periódico El judio errante de Eugène Sue, novela que, luego del éxito rotundo en Le Constitutionnel, venía siendo promocionada en Buenos Aires por la agencia local del Correo de Ultramar. ${ }^{23}$

En consecuencia, puede afirmarse que los últimos años del Diario de la Tarde vaticinan la prensa por venir. Una prensa que, sin desligar nunca sus vínculos con la política -aun con la partisana-, explora y se asienta en la posibilidad de lo versátil, en el desarrollo a tientas de otras vertientes editoriales -la publicidad, los avisos, las ediciones a bajo costo-. Esa exploración, por lo demás, parece evidenciar una demanda hasta ahora poco examinada, la de un público lector expandido, menos interesado en la columna doctrinaria o política que en los espectáculos o el zócalo del periódico.

\section{A modo de conclusión}

A comienzos del siglo XIX los periódicos instalaron una novedosa modalidad de intervención e intercambio públicos. La búsqueda del unanimismo revolucionario, como ocurrió en Francia, en lugar de acotar el circuito propulsó la expansión de libelos y periódicos esporádicos, destinados a perecer entre batallas verbales y asonadas militares. El recurso al anonimato, la máscara del comunicado, como denunciaba Alberdi, presentaba no obstante una doble cara: por un lado, era efectivamente un modo de enmascarar la palabra soberana, la palabra civil, que no parecía multiplicarse fácilmente en su superficie; por el otro, cobraba un valor simbólico y efectivo, el de instrumentar nuevas modalidades de definición del espacio público.

En este sentido, resulta sugerente señalar que una de las prácticas periodísticas tardo-coloniales que habilitarían el pasaje a un nuevo tipo de función publicitaria subsistirá como elemento residual en la prensa liberal y romántica de las décadas del 30 y del 40, aunque los motivos de esa persistencia, por supuesto, sean disímiles. Así explica Annick Lempérière el sutil deslizamiento de la función que cumplían las publicaciones amparadas por las autoridades reales hacia el fin de la Colonia: "Con el pretexto de dar a conocer informaciones útiles y acertadas, el periódico escenificaba opiniones. Se trata de una escenificación, e incluso de una ficción, puesto que el editor, según el privilegio de imprimir, era el único autor de los artículos publicados" (1998, p. 70). Aunque amparado en un pacto de lectura mediado por otros intereses, el recurso de escenificación o ficcionalización de las opiniones aparecerá, como vimos, de modo recurrente en las publicaciones de las nuevas élites letradas.

Uno de los aspectos más interesantes que, en este sentido, merecen ser ahondados en la investigación, es el que permite reponer o recobrar, aunque sea tentativamente, el acceso efectivo de las capas medias -trabajadores asalariados, peones rurales, milicias, maestros- a la lectura de impresos, y a su materialidad.

Me he ocupado de este tema en otro trabajo. (Ver Pas, H. "Eugène Sue en Buenos Aires. Edición, circulación y comercialización del folletín durante el rosismo, en: Varia Historia. Belo Horizonte, Vol. 34, Nro. 64, jan/abr, 2018, pp. 193-225). 
Como vimos aquí a través de los datos de costos, precios y salarios, a comienzos de la década de 1830 resultaba significativamente más gravosa la compra de papeles públicos que una década antes cuando, paradójicamente, se supone que el público lector comenzaba lentamente a expandirse. El alto costo relativo del impreso nos permite reevaluar no sólo la escasez de ventas de muchos periódicos y, consecuentemente, la necesidad de un sostén institucional fijo, sino también la diferencia que plantea el sistema de ventas y suscripción de la prensa alternativa, no hegemónica, como es el caso de las gacetas populares -en el Río de la Plata, en particular la gauchesca- o el de la venta por entregas de novelas o folletos -modalidad en la que incursionó por primera vez en Buenos Aires el Diario de la Tarde-, todas disposiciones que apuntan a un público consumidor más amplio y menos potentado. El periódico, en ese esquema, permitiría con el tiempo ampliar los límites, o romperlos, para dar paso a una lectura masiva. Y, también, a una apropiación política de mayor alcance.

\section{Bibliografía}

Amaral, S. E. (1981). "El descubrimiento de la financiación inflacionaria. Buenos Aires, 1790-1830". Investigaciones y Ensayos, № 37, Academia Nacional de la Historia.

Baker, K. M. (1987). "Politique et opinion publique sous l'Ancien Régime”. Annales. Économies, Sociétés, Civilisations. 1987: 55-57.

Barba, F. E. (1999). Aproximación al estudio de los precios y salarios en Buenos Aires desde fines del siglo XVIII hasta 1860. La Plata: Universidad Nacional de La Plata.

Djenderedjian, J. y Martirén, J. L. (2016). "Measuring living standards. Some caveats concerning salary elements in pre-modern Rio de la Plata region, 1770-1830". Conferencia. January.

Furlong, G. (1953). Historia y bibliografia de las primeras imprentas rioplatenses, 17001850, 2 tomos. Buenos Aires: Editorial Guarania.

Gelamn, J. y Santilli, D. (2014). "Los salarios y la desigualdad en Buenos Aires, 1810-1870”, Am. Lat. Hist. Econ. Septiembre-diciembre, pp. 83-115.

Goldman, N. (2008). "Legitimidad y deliberación: el concepto de opinión pública en Iberoamérica, 1750-1850". Jahrbuch für Geschichte Lateinamerikas, Köln/Weimar/Wien, 45: 221-243.

- (2000). "Libertad de imprenta, opinión pública y debate constitucional en el Río de la Plata (1810-1827)". Prismas, Revista de historia intelectual, 4: 9-20.

González Bernaldo De Quirós, P. (2008). Civilidad y política en los orígenes de la nación argentina. Las sociabilidades en Buenos Aires, 1829-1862. Buenos Aires, FCE.

Guerra, F-X., Lempérière, A. et al. Los espacios públicos en Iberoamérica. Ambigüedades y problemas. Siglos XVIII-XIX. México: Centro Francés de Estudios Mexicanos y Centroamericanos-FCE, 1998

Habermas, J. (1986). Historia y crítica de la opinión pública. México: Gustavo Gili.

Halperin Donghi, T. (1982). Guerra y finanzas en los orígenes del Estado argentino (17911850). Buenos Aires: Editorial de Belgrano.

Hortelano, B. (1936). Memorias de Benito Hortelano. Buenos Aires: Espasa Calpe.

Irigoin, María Alejandra (1995). "Moneda, impuestos e instituciones. La estabilización de la moneda corriente en el Estado de Buenos Aires". Anuario del IEHS, pp. 189-218.

Johnson, L. L. (1990). "Salarios, precios y costo de vida en el Buenos Aires colonial tardío". Boletín del Instituto de Historia Argentina y Americana “Dr. Ravignani”, pp. 133-157. 
Molina, E. (2009). El poder de la opinión pública. Trayectos y avatares de una nueva cultura política en el Río de La Plata, 1800-1852. Santa Fe, Universidad Nacional del Litoral.

Ozouf, M. (1988). "'Public Opinion' at the End of the Old Regime”. The Journal of Modern History. Supplement: Rethinking French Politics in 1788, 60: 1-21.

Palti, E. (2007). El tiempo de la politica. El siglo XIX reconsiderado. Buenos Aires: Siglo XXI

Pas, H. (2013). Sarmiento, redactor y publicista. Con textos recobrados de El Progreso (1842-1845) y La Crónica (1849-1850). Santa Fe: Ediciones UNL.

Roman, C. (2017). Prensa, política y cultura visual. El Mosquito (Buenos Aires, 1863-1893). Buenos Aires: Ampersand.

Sabato, Hilda y Alberto Lettieri (comps.) (2003). La vida politica en la Argentina del siglo XIX. Armas, votos y voces. Buenos Aires, FCE.

\section{Periódicos}

El Argos de Buenos Aires (1821-1824)

El Censor (1815)

El Centinela (1822-1823)

El Talismán (1840)

El Teatro de la Opinión (1823-1824)

El Zonda (1839)

La Gaceta de Buenos Aires (1810-1821)

La Gaceta Mercantil (1823-1833)

La Prensa Argentina (1815-1816)

The British Packet (1830-1833) 